\begin{abstract}
APRESENTAÇÃO
"Há homens que lutam um dia e são bons, há outros que lutam um ano e são melhores, há os que lutam muitos anos e são muito bons. Mas há os que lutam toda a vida e estes são imprescindíveis".
\end{abstract}

(Bertold Brecht)

Ao Edmundo Fernandes Dias, companheiro imprescindível de luta e vida, sempre presente.

\title{
Educação e emancipação humana: elementos introdutórios
}

Este dossiê reúne os textos correspondentes a grande parte das conferências que se realizaram nas diversas mesas de debate do V Encontro Brasileiro de Educação e Marxismo (EBEM), que ocorreu entre os dias 11 e 14 de Abril de 2011, nas dependências da Universidade Federal de Santa Catarina (UFSC). O V EBEM é o desdobramento de uma larga história.

O I EBEM realizou-se no campus da Universidade Estadual Paulista (UNESP), na cidade de Bauru, São Paulo, em maio de 2005, e recebeu o título "Marxismo, Ciência e Educação: a práxis transformadora como mediação da produção de conhecimento".

A segunda edição do EBEM aconteceu em agosto de 2006, na Universidade Federal do Paraná (UFPR), com a temática "Marxismo: Concepção e Método".

O III EBEM, com o tema central "A Educação para Além do Capital", ocorreu na Universidade Federal da Bahia (UFBA), em novembro de 2007.

Por sua vez, o IV EBEM, "Socialismo e Educação na América Latina", aconteceu em julho de 2009, no campus da UNESP de São José do Rio Preto, em São Paulo. A plenária deste encontro aprovou a implementação da Associação Brasileira de Educadores Marxistas (ABEM), que havia sido criada em 2007 no III EBEM.

Desde o início, os EBEMs tiveram como objetivo possibilitar a discussão entre investigadores, professores, estudantes, militantes de movimentos sociais e os diversos núcleos de pesquisa no país que abordam o tema da educaçấo e 
suas interfaces com diferentes áreas de conhecimento na perspectiva teóricometodológica do materialismo histórico.

Herdeiro das ediçóes anteriores, o V EBEM, foi organizado pela Associação Brasileira de Educadores Marxistas (ABEM), pelo Grupo de Estudos e Pesquisas em Ontologia Crítica (GEPOC/CED/PPGE/UFSC), pelo Laboratório de Sociologia do Trabalho (LASTRO/CFH/UFSC), pelo Núcleo de Estudos sobre as Transformaçóes no Mundo do Trabalho (TMT/ CFH/UFSC), e pelo Grupo de Estudos e Pesquisas sobre Infância, Educação e Escola (GEPIEE/CED/PPGE/UFSC).

O V EBEM mostrou, em seus números, a vitalidade do marxismo e sua profunda e consolidada presença no campo da educação. Foram mais de mil inscritos, aproximadamente 500 trabalhos foram apresentados em 50 Grupos de Trabalhos, correspondentes a 10 eixos temáticos: Marxismo: Concepção e Método; Marxismo, Educação e Estado; Marxismo, Educação e Trabalho; Marxismo, Educação e Psicologia; Marxismo, Educação e Escola; Marxismo, Educação e Movimentos Sociais; Marxismo, Educação e História; Marxismo, Educação e Arte; Marxismo, Educação e Universidade; Marxismo e Educação Corporal. Ao longo da realização do evento, intensos debates e polêmicas se travaram nas diversas mesas e tudo isso só foi possível graças à imprescindível contribuiçấo de um enorme contingente de pessoas.

O título geral escolhido para o V EBEM foi "Marxismo, Educação e Emancipação humana". A emancipação humana é uma construção histórica, assim como é o próprio homem. Para produção social de sua existência, os seres humanos têm de satisfazer um conjunto de necessidades humanas, que vão do estômago à fantasia, ou seja, da alimentação à arte, passando pela vestimenta, moradia, educação etc ${ }^{1}$. Para tanto, os homens têm de produzir os elementos que possam propiciar a satisfação de suas necessidades humanas, tais como comida, roupa, casa, ônibus, escola, teatro etc. Esses elementos podem ser chamados de meios de subsistência e são produzidos pelos homens por intermédio do trabalho ${ }^{2}$. Por sua vez, para que haja a produção dos meios de subsistência, os homens têm de produzir, por intermédio de seu trabalho, os meios de produçáo, como o trator, a colheitadeira, os sistemas de irrigação e de transporte, as ferramentas, máquinas e equipamentos etc. Os meios de subsistência e os meios de produção formam, em seu conjunto, os valores de uso, ou seja, tudo aquilo que serve para satisfazer necessidades humanas, seja 
de forma imediata - os meios de subsistência, ou de forma mediata - os meios de produçấo ${ }^{3}$. O conjunto dos valores de uso constitui o conteúdo material da riqueza. Assim, uma sociedade é mais ou menos rica quanto mais ou menos produz valores de uso para satisfazer as necessidades humanas dos indivíduos que compóem tal sociedade. A produção de valores de uso, quer dizer, de riquezas, fundamentalmente por meio do trabalho, é o que propicia a produção da própria existência dos homens como tais e, grosso modo, as formas pelas quais os vêm produzindo é o que constitui a história da humanidade, de seus primórdios até o presente.

Ao longo de sua história, os homens foram potencializando sua capacidade de trabalho, ou melhor, foram aumentando ou desenvolvendo a força produtiva do trabalho. O desenvolvimento da força produtiva do trabalho é resultado de uma série de fatores, entre os quais destacaremos três: (1) produção e incorporação de inovaçôes tecnológicas no processo de trabalho, resultado da produção do conhecimento (pesquisa); (2) elaboração e incorporação de novas formas de organização e gestão do trabalho, que, na sociedade contemporânea, também é resultado da produção do conhecimento (pesquisa); (3) qualificação da força de trabalho (educação/formação).

Portanto, a produção de conhecimento (pesquisa), sistematização, acúmulo e sua transmissão para as novas gerações (educação) são elementos decisivos no desenvolvimento da força produtiva do trabalho. O desdobramento de tal desenvolvimento é o aumento da produtividade do trabalho, o que quer dizer a produção de uma quantidade maior de riquezas com um dispêndio relativamente menor de trabalho para satisfação de necessidades humanas em patamares cada vez mais elevados, criando assim as condiçóes materiais para a construção da emancipação humana.

Como pode-se perceber, a educação, em uma relação de constituição mútua com a produção do conhecimento (pesquisa), tem um papel fundamental no processo de construção da emancipação humana. Em seu sentido lato, a educação possibilita a cada indivíduo das novas gerações entrar em contato com todo o legado humano e, portanto, com o que foi produzido socialmente e acumulado historicamente pela experiência humana e, nesse sentido, cria condiçóes de formação de elos entre o indivíduo singular e o gênero humano, pela atividade mediada, o que permite que esse legado se torne órgáos de sua individualidade. Segundo Leontiev (1978, p. 272, grifos do autor), 
[...] as aquisiçôes do desenvolvimento histórico das aptidões humanas não são simplesmente dadas aos homens nos fenômenos objetivos da cultura material e espiritual que os encarnam, mas são aí apenas postas. Para se apropriar destes resultados, para fazer deles as suas aptidóes, 'os órgãos da sua individualidade', a criança, o ser humano, deve entrar em relação com os fenômenos do mundo circundante através de outros homens, isto é, num processo de comunicação com eles. Assim, a criança aprende a atividade adequada. Pela sua função este processo é, portanto, um processo de educação.

A indagação que se impóe é a seguinte: será que na sociedade contemporânea, no capitalismo, o desenvolvimento da força produtiva do trabalho e a educação, como um de seus elementos basilares, têm como escopo a emancipação humana?

O capitalismo é um modo de produção que demanda um desenvolvimento constante e acelerado das forças produtivas para que possa haver um incremento da produtividade. Contudo, sua finalidade não é a satisfação de necessidades humanas e, portanto, a emancipação humana. Então, qual a razão do desenvolvimento da força produtiva do trabalho no capitalismo? Entre outras, destacaremos duas grandes finalidades: (1) a necessidade de diminuição do valor das mercadorias por causa da concorrência intercapitalista; (2) a necessidade de diminuição do valor da força de trabalho que redunda na produção e exploração da mais-valia relativa e, por conseguinte, no aumento no grau de exploração da força de trabalho. Faremos, a seguir, uma breve explanação desses dois fatores.

O desenvolvimento da força produtiva do trabalho, no sistema capitalista, carrega consigo algumas contradições. Tendo em vista duas das contradiçóes básicas do movimento do capital, a saber, a concorrência intercapitalista e a contradição entre as duas classes sociais fundamentais, burguesia e proletariado, o desenvolvimento das forças produtivas torna-se o fator decisivo e fundamental no processo de produção capitalista. Isto porque é por meio do desenvolvimento das forças produtivas, cujo efeito prático é o aumento da produtividade, que os capitalistas logram a diminuição do valor de suas respectivas mercadorias, o que lhes propicia sua sobrevivência no mercado competitivo e, ao mesmo tempo, a redução do valor da mercadoria força de trabalho, que resulta na produção da mais-valia relativa, com a condição de que o incremento da produtividade tenha atingido as cadeias de fabricação dos meios de subsistência necessários 
para produzir a vida do trabalhador. Aumento de produtividade significa, entretanto, a produçáo de uma quantidade cada vez maior de valores de uso com uma grandeza relativamente menor de valor, o que é um problema gravíssimo para o capital, pois redunda na tendência de diminuiçấo da taxa de lucro e de acumulação, já que o capital é resultado de um processo de valorizaçâo do valor e náo de acúmulo de valor de uso, ou seja, de riqueza. Dessa forma, a solução para os capitais privados é um problema para o capital, uma vez que o mecanismo que propicia a sobrevivência dos capitais privados no mercado cria, contraditoriamente, as condições de produção da morte do capital. Capitais privados e capital estabelecem, portanto, uma relaçáo de contradiçáo, de tal sorte que a continuidade da existência deste último implica a destruição, pelo menos parcial, de capitais privados, e vice-versa.

Náo obstante, tal processo se efetiva justamente porque, dada a concorrência intercapitalista, há uma necessidade de diminuição do valor das mercadorias, o que só pode ser conseguido com o desenvolvimento das forças produtivas e, por conseguinte, com o aumento da produtividade, que exige, por sua vez, a utilização relativamente menor da força de trabalho, ou seja, o dispensamento tendencial desta mercadoria que entra no processo de produçáo como capital variável, em detrimento da crescente utilizaçáo relativa do capital constante, redundando no aumento da composição orgânica do capital e, por decorrência, em uma diminuição de sua taxa de acumulaçáo.

Por essa razão, e tendo em vista que há uma redução relativa do número de trabalhadores a serem explorados e uma quantidade relativamente crescente de força de trabalho dispensada, ocorre uma depreciação do valor individual da força de trabalho provocando um arrocho salarial entre os trabalhadores que ainda continuam a ter o privilégio de vender sua força de trabalho e a serem explorados, num processo infindável e ininterrupto. $\mathrm{O}$ que se assiste aqui é uma dupla forma de destruição da força de trabalho. De um lado, a força de trabalho supérflua, que foi produzida pelos trabalhadores como valor de troca, mas que, não sendo valor de uso para o capital, é totalmente aniquilada, engrossando as estatísticas do desemprego, fenômeno que, pelas razóes expostas, é insolúvel nos marcos do capitalismo. De outro lado, a força de trabalho ainda aproveitada e consumida pelo capital, que, tendo em vista a diminuiçáo de seu valor individual, não consegue se reproduzir a não ser de forma atrofiada e débil, comprometendo sua própria condiçáo de produtora de mais-valia e de capital. Esses dois lados da mesma moeda, desemprego e arrocho salarial, expressam, em 
sua relação umbilical e orgânica, a destruição necessária da força de trabalho realizada pelo capital. Aqui pode-se vislumbrar uma das grandes contradições do processo de acumulação, pois para se produzir e se reproduzir, o capital é obrigado a destruir força humana de trabalho, e ao fazê-lo destrói sua única fonte de criação. Soma-se a essa contradição, em uma relação também contraditória, a contradição apontada anteriormente entre o capital e os capitais privados, e constata-se, como resultado dessa equação, que o capital produz sua vida com a condição de produzir sua morte.

A produção de uma maior quantidade de valores de uso, que constitui o conjunto da riqueza de uma sociedade, para a satisfação das necessidades humanas com a menor quantidade possível de trabalho é o elemento propulsor do movimento de produção e reprodução do capital e, ao mesmo tempo, como desdobramento daquela contradição original, o fator de seu próprio aniquilamento. As crises de superprodução de capital são a maior expressão desse processo de contradição. Assim, o desenvolvimento das forças produtivas propicia, a um só tempo, a vida e a morte do capital. Trata-se, no fundo, da contradiçấo imanente e inexterminável no capitalismo entre a valorizaçáo do valor (o capital) e o valor de uso (a riqueza); entre o trabalho produtivo de capital e o trabalho concreto; entre o capital e a satisfação das necessidades humanas; entre o capital hominizado e o ser social reificado; em suma, entre o capital e a humanidade.

Por isso, no capitalismo a construção do gênero humano se dá pela sua destruição, a sua emancipação se efetiva pela sua degradação, a produção de sua vida se realiza pela produção de sua morte, a produção de sua morte é condiçẫo para a produção de sua vida. $\mathrm{Na}$ forma social do capital, a construçâo do ser humano se processa pela sua niilização, a afirmação de sua condição de sujeito se realiza pela negação dessa mesma condição, sua hominização se produz pela produção de sua reificação.

Portanto, a emancipação humana, em sua plenitude, não pode realizar-se no interior do capitalismo. Sua plena realização pressupóe a superação desse sistema sócio-metabólico, o que implica uma revolução contra essa ordem, que demanda, por sua vez, a elaboraçáo e implementação de uma estratégia revolucionária.

Não podemos esquecer o papel que desempenhou a revolução na história da humanidade. Os modos de produção foram gestados a partir de revoluçóes sociais, e o modo de produção vigente, o capitalismo, também ele nasceu de uma revolução. 
Dessa forma, para nós, educadores marxistas, o desafio que se põe é o de discutir o papel da educação como componente de uma estratégia revolucionária que busque a superação desse modo de produção, tendo em vista a construção de uma sociedade comunista.

Seguramente, essa foi a característica marcante da produção teóricopolítica de praticamente todos os autores-militantes marxistas que se dedicaram, no Brasil, à temática da educação em vários momentos do século XX, cujo auge ocorreu entre o final dos anos 1970 e o início da década de 1990. Em clara sintonia com a conjuntura política brasileira desse período, cuja marca mais distintiva foi a ascensão das lutas dos movimentos sociais, a produção teórica daqueles autores, fundamentada, principalmente, na contribuição de Antonio Gramsci, buscou estabelecer uma relação entre a educação e uma estratégia de superação do capitalismo.

Não obstante, parece-nos que tal situação foi se alterando gradativamente ao longo da década de 1990, já que a discussão a respeito do vínculo entre a educação e a estratégia revolucionária foi se arrefecendo, acompanhando o processo histórico marcado por uma conjuntura de profundo refluxo das lutas sociais e de flagrante derrota da classe trabalhadora, de tal maneira que a imensa maioria dos movimentos e organizaçóes dos trabalhadores, no mundo inteiro, abandonou os últimos resquícios de um projeto revolucionário, de confrontação com a ordem capitalista.

A história vem demonstrando que, na passagem do milênio, provavelmente a revoluçấo nunca esteve táo desacreditada e, portanto, táo ausente das discussóes da esquerda em todos os âmbitos. De fato, nunca foi tão difícil falar sobre e construir a revolução, resumidamente, porque: o projeto societal do capital saiu vitorioso e se impôs em todo planeta; produziu-se uma derrota e um profundo refluxo do movimento da classe trabalhadora; por isso, há um abandono do projeto revolucionário e, por desdobramento, também do referencial teóricopolítico que dá sustentação a este projeto, o marxismo.

Contudo, pensamos que, paradoxalmente, nunca foi tão necessário falar sobre e construir a revolução, pelas seguintes razões: (1) vitorioso, o capital "foi jogado a sua própria sorte”, ou seja, a suas próprias contradiçóes, que acirram a cada dia; (2) por causa de sua própria lógica, de seu movimento contraditório, o capital nunca mostrou de forma táo enfática, como nos tempos atuais, sua capacidade destrutiva, do homem e da natureza, no plano global; (3) daí, a crise estrutural do capital, conforme denomina Mészáros, ou, como preferimos 
entender, crise estrutural de produção da sociabilidade humana na forma capital; (4) nunca a contradição antagônica entre capital e humanidade ficou tão evidente e constatável empiricamente como no período contemporâneo, ou seja, nunca a continuidade da existência humana esteve tão ameaçada por um modo de produçáo gestado pela própria humanidade.

Por outro lado, uma análise do século XX nos permite extrair algumas conclusões que podem facilitar o empreendimento revolucionário. O século passado comprovou cabalmente que não se pode ter mais nenhuma ilusão: (1) de que o capitalismo possa oferecer alguma saída para a humanidade em direção a sua plena emancipação; (2) de que é possível reformar substantivamente o capitalismo; (3) de que a estratégia social-democrata, seja a de reformas do capitalismo, seja a de tentativa de superaçáo da ordem capitalista por meio da ocupação dos espaços institucionais, de participação no governo etc., possa alcançar algum êxito. O período da passagem do século XX para o XXI evidencia que nunca foi tão gritante o lema "socialismo ou barbárie", o que implica "revolução ou barbárie".

Se a revolução se impóe como tão necessária, na mesma medida se impóe a necessidade de se retomar, num novo patamar, a grande questão que orientou a produção teórica marxista na educação durante a década de 1980: como a educação pode contribuir com o processo de transformação revolucionária do capitalismo?

Esse foi o grande desafio posto para os educadores marxistas reunidos no V Encontro Brasileiro de Educação e Marxismo: restabelecer as discussóes da educação e seu vínculo com o empreendimento revolucionário. Foi com tal desafio colocado no horizonte que os componentes das mesas realizadas durante o evento ofereceram suas contribuiçóes.

Dessa forma, neste volume 31, a Revista Perspectiva apresenta o dossiê Marxismo, Educação e Emancipação Humana. A organização do mesmo é composta por seis artigos e um debate de autoria de alguns participantes das mesas do V EBEM, e a entrevista com o Professor Diego Jorge Gonzalez Serra.

O artigo de Fernando Ponte de Sousa, O Estado e a educaçáo na perspectiva da classe trabalhadora, apresenta um rico debate sobre a centralidade do trabalho e a centralidade da classe trabalhadora, distinção que realiza com esclarecedoras argumentaçóes. Nesse contexto, apresenta e discute as limitaçóes da categoria trabalho quando abordada fora do contexto histórico- 
cultural, bem como os desdobramentos dessa categoria na análise da educação. Explica como a "centralidade política do capital é a substância do que parece ser uma retomada da centralidade do trabalho" e, nessa direção, retoma criticamente a vertente existente sobre uma concepção de que a educaçáo pensada como princípio educativo corresponderia à perspectiva da classe trabalhadora. $\mathrm{O}$ autor insiste que o que faz existir como superação e emancipação - relação entre o Estado e educaçáo sob a ótica da classe trabalhadora - é a "[...] negaçáo da negação, é colocar o Estado e a educação sob outra centralidade, a centralidade política da revolução". Esta é, historicamente, a real centralidade do trabalho, como negação radical do trabalho produtivo de capital. Assim, Sousa nos deixa a instigante reflexão e pergunta: a partir da classe trabalhadora, é possível pensar a relação entre o Estado e a Educação na perspectiva revolucionária. Mas se isso não for tolerado dentro da ordem em que estamos?

Continuando a discussáo de Sousa, mas aprofundando a concepçáo do papel do Estado na produçáo capitalista e sua relaçáo com a educação, Beatriz Rajland, em seu texto Estado, Emancipación y Educación: una aproximación desde el pensamiento marxista, afirma a concepçáo do Estado "[...] como um produto da sociedade e como um estado de classe [que], por um lado, assegura a reprodução do modo de produção de uma sociedade, e por outro, também é o lugar da luta de classe, um lugar de disputa". Frente a essa realidade, a autora explica que necessita uma ação política já que é "fundamental uma contra hegemonia e a educaçáo é um dos instrumentos importantes para tal fim”. Apresenta, primeiramente uma explicação do significado de Estado, reconhecendo-o como uma categoria polêmica - em especial quando considerada abstrata. Assim, Rajland, vai "impugnar essa forma de abordagem" para interpelar seu 'rol', colocando maior atenção na caracterizaçáo do Estado, em especial para compreender que relaçóes sociais é portador.

As questôes de como se origina o Estado, qual sua relação com a sociedade civil, que lugar ocupa na economia, a que interesses serve sua ação e de que forma a realiza, orientam o desenvolvimento do texto e ajudam o leitor a começar antecipadamente a pensar sobre tais questôes de forma crítica. A discussão exposta por Rajland explora - dentro dos limites que exige um artigo-, detalhes e desdobramentos históricos para entender o Estado capitalista, mostrando características de sua funçáo e de sua objetividade enquanto relaçáo social. Ao debater sobre a emancipação e a educação, a autora afirma que; "[...] a emancipação não se constrói por partes isoladas". Na busca de construir condições 
para a emancipação torna-se necessário cimentar uma contra hegemonia como contrapoder. Nesse sentido, pergunta: a luta se dá pela educação em direção à emancipação ou pela emancipação à educação? A educação é um dos instrumentos importantes, mas difícil sem a prática política dos sujeitos conscientes. Indica que a tarefa dos educadores marxistas tem que ir além da educação formal, incluindo a formação dos movimentos sociais e políticos, cursos de formação que priorizem o tema da desmistificação do capital, desnaturalização do capitalismo, ou seja, aprofundar as características do capitalismo da época, sendo isto fundamental para produzir uma ruptura revolucionária.

Por sua vez, Mauro Iasi afirma, em seu artigo Educaçáo, consciência de classe e estratégia revolucionária, a importância do desenvolvimento da consciência de classe, e as estratégias da educação em um contexto de apassivamento da classe trabalhadora. Para tal fim, o autor desenvolve o conceito de ideologia e, em seu percurso, enfatiza "[...] a importância de controlar os centros de produção e disseminação do conhecimento, como, por exemplo, as universidades, o mercado editorial, os centros de formação, de pesquisas e de desenvolvimento de tecnologias, ou, ainda, de demarcar o campo de possibilidades e a forma de divulgação e disseminação do conhecimento acumulado nos aparelhos escolares". Isto explica o poder de uma classe em apresentar a visão do mundo como sendo universal, mas, esclarece Iasi, não explica porque os trabalhadores explorados nessa ordem aceitam como suas as ideias de seus adversários. Dessa forma, o autor analisa detalhadamente a questão da consciência e afirma que ela somente pode se originar e se desenvolver "[...] como expressão de relações que constituem o fundamento da sociabilidade humana, isto é, ela não é uma força que se impóe ao humano como a Ideia hegeliana ou sua expressão no Espírito objetivo ou no Espírito Absoluto". Assim, Iasi esclarece que a classe trabalhadora é ao mesmo tempo “[...] uma classe da ordem do capital e por isso expressa na sua consciência os elementos do amoldamento e, exatamente por ser uma classe da ordem do capital, pode entrar em choque com esta ordem almejando ir além dela e, quando o faz, expressa uma consciência que pode chegar a uma consciência de classe”.

Nessa direção, a discussão articula consciência e relaçóes de produção que são bases da expressão ideológica, para depois perguntar qual seria o papel da educação, seja ela pensada no campo da educação formal ou no contexto de práticas alternativas. Iasi reconhece - e não poderia ser diferente - que os 
trabalhadores, na imagem gramsciana, “[...] devem fazer seu inventário, resgatar do conhecimento universal mais desenvolvido as bases para constituição de sua autonomia de classe, desvelando os fundamentos políticos e os interesses de classe que perpassam o conhecimento e as formas educativas e esta é uma tarefa que passa pela socializaçáo do conhecimento nos espaços formais, mas exige que saibamos construir nossos próprios espaços formativos, pois certos temas e formas educativas exigem espaços próprios e independentes".

John Bellamy Foster, em seu texto Educaçáo e a crise estrutural do capital: o caso dos Estados Unidos, nos apresenta uma interessante e profunda discussão em relação à educação pública nos Estados Unidos. Destaca que o movimento conservador pela reforma da educação pública nos Estados Unidos, e em grande parte do mundo, é baseado na opinião predominante de que a educação pública encontra-se em um estado de emergência, diante desse discurso amplamente conhecido, vem surgindo há várias décadas a "urgente" necessidade de reformas e reestruturaçóes para poder subsanar "as próprias falhas internas", como bem indica o autor. Frente a essa realidade, a premissa que Foster apresenta no início do texto é de que "[...] a decadência do ensino público é, principalmente, um produto de contradiçóes impostas externamente que são inerentes à educação na sociedade capitalista, agravadas em nossos tempos pelas condiçóes de estagnação econômica nas economias capitalistas desenvolvidas e pelos efeitos do próprio movimento de reforma conservador". Para tal fim, o autor apresenta os pressupostos da política educacional, os desdobramentos e consequências para a educação pública, realizando uma forte crítica a partir de uma perspectiva histórica da relaçáo capital e educação no contexto da crise estrutural do capital nos Estados Unidos. No decorrer do texto explicita-se a crise estrutural associada a uma nova fase do capitalismo: o capital monopolista-financeiro, caracterizada pela estagnaçáo econômica nas economias capitalistas desenvolvidas; mudança dramática em direçáo à financeirização, (as bolhas especulativas como meio de expansão econômica); e a rápida concentração (e monopolização) de capital em uma escala global". Assim, Foster afirma "[...] que as grandes corporaçóes que dominam a economia mundial atual são obrigadas a procurar novos mercados para investimento, fora de suas áreas tradicionais de atuação, levando à aquisição e privatização de elementos-chave da administraçáo do Estado". Apoiado em argumentaçóes consistentes, o autor apresenta tal situaçáo como uma consequência do lento crescimento endêmico para as economias desenvolvidas. 
A partir de diversos autores da área econômica que discutem a educação e com base em Marx, o texto informa e explicita as relaçóes entre os diferentes elementos que compóem a degradação e desvalorização da educação pública. Finaliza suas análises indicando a necessidade de uma longa revoluçâo, para criar, entre outras coisas, uma nova educação ligada à comunidade, e desenvolvida a partir das necessidades reais das pessoas.

Celi Taffarel, no artigo As teses de abril de 2011 sobre educaçáo, consciência de classe e estratégia revolucionária, apresenta algumas proposições relacionadas à educaçáo e sua relação com a consciência de classe e estratégias revolucionárias da classe trabalhadora. Inicia seu texto explicando a função social da escola, o papel dos trabalhadores em educação, sua formação, remuneração, assistência, saúde, previdência, o trabalho socialmente útil como princípio educativo e o financiamento da educação. Posteriormente, a autora articula as propostas da educação, inscritas no conjunto de reivindicaçóes particulares da classe trabalhadora brasileira no momento histórico, e indica que estes trabalhadores "[...] travam uma forte luta de classes que se expressa em três âmbitos - econômico, político e ideológico". Alerta também que "[...] a luta mais geral da classe trabalhadora é a formação econômica e sua revolução, ou seja, no modo de vida e sua superação, e os indicadores de que a humanidade superou uma velha fase para ingressar em uma nova formação econômica e, correspondendo a ela uma nova superestrutura jurídica e ideológica”.

A autora reconhece que as estratégias no campo da revolução permanente, quer dizer, na luta de curto, médio e longo prazo que está em curso para superar o capitalismo, acontecem concomitante, com processos "[...] contrarevolucionários e a necessidade histórica da ofensiva em todos os âmbitos - singular, particular e geral - ou seja, da luta pelas reivindicaçóes específicas da educação, das reivindicaçóes em geral dos trabalhadores brasileiros e, a luta pelas reivindicações históricas dos trabalhadores no mundo".

Alejandro Gonzalez, em seu artigo Propuestas sobre el Arte y la Educación, nos oferece, a partir de uma relação entre objetivaçóes genéricas - necessárias para produzir aprofundamentos e conceitualizaçóes dos fenômenos do real -, uma interessante análise de como a arte possibilita e amplia a compreensão do mundo objetivado. A partir da perspectiva histórico-cultural, em especial de Vigotsky, defende a livre discussão da arte nos processos educacionais e como o modo metafórico que processa a informação ajuda e favorece a gerar avanços na direçấo da apropriação do pensamento 
científico. Cabe destacar que o enfoque mais pontual do autor não dispensa nem deixa de lado uma concepçấo de sujeito atrelado ao modo de produção capitalista, ao contrário, explica - desde uma perspectiva histórica - como as "individualidades nascem carregadas pelas qualidades inerentes ao sistema, de um espírito majoritariamente competitivo". Nesse contexto é que consolidam-se as instituiçôes educacionais como "geradoras de indivíduos competitivos entre si”. Mas, também, explica Gonzalez, a escola, além de transmitir conhecimentos, os exercita para os usos de ferramentas do pensamento, gerando diferentes níveis de habilidades em sua utilização. $\mathrm{Na}$ maioria das vezes, essas práticas se realizam adaptando-se às regras que o próprio sistema induz, ou seja, nos termos do autor, coloca o sujeito em um lugar preponderantemente passivo, um mero aplicador de técnicas desenhadas por outros.

Mas, ao contrário dessa posição, defender a educação fundamentada em uma proposta marxista implica algo diferente. Principalmente quando se trata de produzir condiçóes de subjetivaçáo que favoreçam desenvolvimentos com plenas capacidades de discernimento e pensamento autônomo. A partir destas questóes, o autor vai expressar pontos de análise em relaçáo à transmissão criativa, utilizando aportes de autores como Lakoff e Johnson e da psicanálise, em especial de Freud, para depois transitar no campo da arte, campo "privilegiado da metáfora, do sentido pessoal, ou, como Vigotsky diz, do instrumento social do sentimento".

Assim, o autor mostra, em seu artigo, como a arte na educação brinda apoios inestimáveis, e como, com base na teoria histórico-cultural, é possível conhecer os íntimos mecanismos a partir dos quais isto é possível.

$\mathrm{Na}$ seção de debate da Revista, Dermeval Saviani, no texto intitulado Debate sobre as relaçóes entre educaçáo, formaçáo humana e ontologia a partir do método dialético, busca analisar as relaçōes entre educação, formação humana e ontologia a partir do método desenvolvido por Marx e, com base nessa análise, estabelece uma interlocução crítica com a tese de doutorado A relação entre capital e educação escolar na obra de Dermeval Saviani: apontamentos críticos.

Primeiramente, Saviani situa o debate em torno da tese, faz uma explanação acerca do significado do método dialético e prossegue fazendo um esclarecimento das controvérsias suscitadas pela referida tese, e também por textos de outros autores marxistas, ilustradas por meio de alguns exemplos. Ao final, o autor destaca o significado da pedagogia histórico-crítica, como teoria da educação construída no âmbito do marxismo. 
A entrevista com o professor Diego Jorge Gonzalez Serra, professor honorário da Cátedra Vigotsky da Faculdad de Psicología da Universidad de La Habana, Cuba, realizada durante I Congresso Internacional sobre a Teoria Histórico-Cultural e XI Jornada do Núcleo de Ensino, em Marília, São Paulo, traz contribuiçôes preciosas para o estudo das relaçóes entre educação e desenvolvimento humano.

Gonzalez Serra inicia a entrevista com o contexto da vida e obra de Rubinstein e seus principais aportes teóricos, destacando que Vigotsky originalmente o antecedeu. As relações entre as ideias de Rubinstein, Leontiev e Galperin também são estabelecidas e trazem elementos instigantes para futuras investigaçôes. Ao explicitar o "principio de la unidad dialéctica de la psiquis y la actividad", aborda temas como: motivo, motivação, apropriação, unidade de contrários e destaca o papel ativo do sujeito. Nesse movimento oferece as bases para a formulaçáo de princípios teórico-metodológicos orientadores da atuação político-pedagógica.

Esperamos que a leitura dos textos permita enriquecer os debates táo necessários para o avanço do conhecimento, da práxis e do campo de possibilidades que está posto no movimento da história e almejamos, sobretudo, que possa contribuir para a compreensão da relação entre educação, processo revolucionário e emancipação, já que a revolução é a parteira da história, grávida de uma nova sociedade, na qual a emancipaçáo humana poderá se realizar plenamente.

\author{
Paulo Sergio Tumolo \\ Patrícia Laura Torriglia \\ Maria Isabel Batista Serrão \\ Organizadores
}

\title{
Notas
}

${ }^{1}$ Essas necessidades humanas são historicamente determinadas, uma vez que o homem é um ser historicamente determinado, o que significa dizer que elas vão se alterando ao longo de sua história, acompanhando o desenvolvimento das forças produtivas. 
${ }^{2}$ Parece-nos que a compreensão sintética mais elaborada sobre o trabalho em geral pode ser encontrada em Marx (1983, p. 149).

${ }^{3}$ Em geral, os valores de uso são resultado do trabalho humano. Contudo, há valores de uso que têm como fonte a natureza, sem que tenha havido intervenção humana. Assim é o caso, por exemplo, da terra virgem, que é o meio de produção originário, e do ar que respiramos, que é um meio de subsistência.

\section{REFERÊNCIAS}

LEONTIEV, A. O desenvolvimento do psiquismo. Tradução de Manuel Dias Duarte. Lisboa: Livros Horizonte, 1978.

MARX, Karl. O Capital. São Paulo: Abril Cultural, 1983. 1v., tomo 1. 